\title{
Retrospective Cohort Study of Lassa Fever in Pregnancy, Southern Nigería
}

Sylvanus Okogbenin, Joseph Okoeguale, George Akpede, Andres Colubri, Kayla G. Barnes, Samar Mehta, Reuben Eifediyi, Felix Okogbo, Joseph Eigbefoh, Mojeed Momoh, Mojeed Rafiu, Donatus Adomeh, Ikponmwosa Odia, Chris Aire, Rebecca Atafo, Martha Okonofua, Meike Pahlman, Beate Becker-Ziaja, Danny Asogun, Peter Okokhere, Christian Happi, Stephan Günther, Pardis C. Sabeti, Ephraim Ogbaini-Emovon

\section{Medscape ACTIVITY}

In support of improving patient care, this activity has been planned and implemented by Medscape, LLC and Emerging Infectious Diseases. Medscape, LLC is jointly accredited by the Accreditation Council for Continuing Medical Education (ACCME), the Accreditation Council for Pharmacy Education (ACPE), and the American Nurses Credentialing Center (ANCC), to provide continuing education for the healthcare team.

Medscape, LLC designates this Journal-based CME activity for a maximum of 1.00 AMA PRA Category 1 Credit(s) ${ }^{\mathrm{TM}}$. Physicians should claim only the credit commensurate with the extent of their participation in the activity.

Successful completion of this CME activity, which includes participation in the evaluation component, enables the participant to earn up to $1.0 \mathrm{MOC}$ points in the American Board of Internal Medicine's (ABIM) Maintenance of Certification (MOC) program. Participants will earn MOC points equivalent to the amount of CME credits claimed for the activity. It is the CME activity provider's responsibility to submit participant completion information to ACCME for the purpose of granting ABIM MOC credit.

All other clinicians completing this activity will be issued a certificate of participation. To participate in this journal CME activity: (1) review the learning objectives and author disclosures; (2) study the education content; (3) take the post-test with a $75 \%$ minimum passing score and complete the evaluation at http://www.medscape.org/journal/eid; and (4) view/print certificate. For CME questions, see page 1624.

Release date: July 16, 2019; Expiration date: July 16, 2020

Learning Objectives

Upon completion of this activity, participants will be able to:

- $\quad$ Compare maternal and fetal outcomes for 2 broad patterns of clinical presentation in 30 pregnant patients with LF: patients with complications vs patients with milder, nonspecific symptoms, according to a retrospective study of cases seen at ISTH n Nigeria between January 2009 and March 2018

- Describe predictors of maternal and fetal outcomes in 30 pregnant patients with LF treated with early ribavirin and a conservative obstetric approach at ISTH in Edo State, Nigeria, between January 2009 and March 2018, according to a retrospective study

- Identify clinical implications of maternal and fetal outcomes in 30 pregnant patients with LF treated with early ribavirin and a conservative obstetric approach at ISTH in Edo State, Nigeria, between January 2009 and March 2018, according to a retrospective study.

\section{CME Editor}

Jude Rutledge, BA, Technical Writer/Editor, Emerging Infectious Diseases. Disclosure: Jude Rutledge has disclosed no relevant financial relationships.

\section{CME Author}

Laurie Barclay, MD, freelance writer and reviewer, Medscape, LLC. Disclosure: Laurie Barclay, MD, has disclosed no relevant financial relationships.

\section{Authors}

Disclosures: Sylvanus Okogbenin, MBBS, FWACS; Joseph Okoeguale, MBBS, MSc, FWACS; George O. Akpede, FWACP, FMC Ped; Andres Colubri, PhD, MFA,; Kayla Barnes, PhD; Samar Mehta, MD, PhD; Reuben Eifediyi, MBBS, FMCOG, FWACS; Felix Okogbo, MBBS, FWACS, FICS; Joseph Eigbefoh, MBBS, FMCOG, FWACS, FICS; Mojeed Momoh, MBBS, FWACS, FICS; Mojeed Olaitan Rafiu, MBBS, FMCP; Donatus Adomeh, PhD, MSc, AMLSCN, FMLSCN; Ikponmwosa Odia, MSc; Chris Okafi Aire, FMLSCN, BMLS; Rebecca O. Atafo, BScH/Fel, BSc Nursing, HMD PUB/H; Martha Okonofua, RN, RM, LLM, LLB; Meike Pahlman, PhD; Beate Becker-Ziaja; Danny Asogun, MBBS, MHPM, MD; Peter Okokhere, MBBS, FWACP; Christian Happi, PhD; Stephan Günther, MD; and Ephraim Ogbaini-Emovon, MBBS, MPH, FMCPath, have disclosed no relevant financial relationships. Pardis Sabeti, MD, DPhil, MSc, has disclosed the following relevant financial relationships: served as an advisor or consultant for NextGen Jane, Sherlock Biosciences; owns stocks, stock options, or bonds from NextGen Jane, Sherlock Biosciences, TruGenomix, Inc. 
Lassa fever in pregnancy causes high rates of maternal and fetal death, but limited data are available to guide clinicians. We retrospectively studied 30 pregnant Lassa fever patients treated with early ribavirin therapy and a conservative obstetric approach at a teaching hospital in southern Nigeria during January 2009-March 2018. Eleven (36.7\%) of 30 women died, and 20/31 (64.5\%) pregnancies ended in fetal or perinatal loss. On initial evaluation, $17 / 30$ (56.6\%) women had a dead fetus; $10 / 17(58.8 \%)$ of these patients died, compared with $1 / 13(7.7 \%)$ of women with a live fetus. Extravaginal bleeding, convulsions, and oliguria each were independently associated with maternal and fetal or perinatal death, whereas seeking care in the third trimester was not. For women with a live fetus at initial evaluation, the positive outcomes observed contrast with previous reports, and they support a conservative approach to obstetric management of Lassa fever in pregnancy in Nigeria.

$\mathrm{L}$ assa fever (LF), a viral hemorrhagic fever endemic to West Africa (1-3), was first reported in 1969 from northern Nigeria $(4,5)$. Since that time, LF has been documented in several countries in West Africa, including Sierra Leone, Liberia, Guinea, Mali, and, more recently, Benin and Togo (6-9). Historical reports of LF in pregnancy have described poor maternal and fetal outcomes; an early direct comparison in Sierra Leone reported a 50\% mortality rate in pregnant women $(n=30)$, compared with $16 \%$ among nonpregnant women $(\mathrm{n}=234)(10)$. A subsequent study conducted in Sierra Leone in 1988 observed a smaller disparity of a $21 \%$ mortality rate in pregnant women $(\mathrm{n}=68)$ versus $13 \%$ among nonpregnant women $(\mathrm{n}=79)$ but found a worse mortality rate $(30 \%, \mathrm{n}=40)$ for mothers in the third trimester and an overall fetal and

Author affiliations: Institute of Lassa Fever Research and Control, Irrua Specialist Teaching Hospital, Irrua, Nigeria (S.A. Okogbenin, J. Okoeguale, G. Akpede, R. Eifediyi, F. Okogbo, J. Eigbefoh, M. Momoh, M. Rafiu, D. Adomeh, I. Odia, C. Aire, R. Atafo, M. Okonofua, D. Asogun, P. Okokhere, E. Ogbaini-Emovon); Ambrose Alli University Faculty of Clinical Science, Ekpoma, Nigeria (S.A. Okogbenin, G. Akpede, D. Asogun, P. Okokhere), Broad Institute of MIT and Harvard, Cambridge, Massachusetts, USA (A. Colubri, K.G. Barnes, S. Mehta, P.C. Sabeti); Harvard University, Cambridge (A. Colubri, P.C. Sabeti); Beth Israel Deaconess Medical Center, Boston, Massachusetts (S. Mehta); Bernhard Nocht Institute for Tropical Medicine and German Centre for Infection Research, Partner Site, Hamburg, Germany (M. Pahlman, B. Becker-Ziaja, S. Günther); Department of Biological Sciences and African Center of Excellence for Genomics of Infectious Diseases, Redeemer's University, Ede, Nigeria (C. Happi); Harvard School of Public Health, Boston (P.C. Sabeti)

DOI: https://doi.org/10.3201/eid2508.181299 neonatal mortality rate of $87 \%$ (11). Although the Sierra Leone study demonstrated the considerable contribution of LF to overall maternal mortality rates at a single hospital, since then, large studies of pregnant patients with LF have been lacking, leading to difficulty in estimating the actual regional burden on maternal health. This problem is exacerbated by the large variability in Lassa virus across regions (12) and the often nonspecific early signs and symptoms of the disease, including overlap with other common infectious diseases in the region, such as malaria, influenza, and bacterial sepsis $(2,13)$.

Pathophysiologically, the poor outcome of LF in pregnancy has been attributed to the higher viral loads often observed in pregnant compared with nonpregnant patients, possibly because of the poorly understood immunologic changes in pregnancy or the affinity of the virus for the highly vascularized placenta $(14,15)$. Also, the overlap of symptoms such as nausea, headache, and abdominal pain with complicated or even uncomplicated pregnancy might further delay identification or diagnosis and result in worse outcomes when the infection is severe (16).

The management of LF in pregnancy requires making difficult decisions with sparse data for guidance. The antiviral drug ribavirin represents the only established pharmacologic therapy for LF and is believed to substantially reduce overall mortality rates $(17,18)$, although the mechanism of action is not clear and data on safety of the drug in pregnancy are limited (19). The 1988 Sierra Leone study, which has been the largest LF case series in the literature to date, found that delivery, spontaneous abortion (miscarriage), and evacuation of the uterus all improve maternal outcome (11); the study recommended active obstetric management, particularly because the authors observed high fetal mortality rate irrespective of the modality of management (2). However, patients in the study did not receive ribavirin before delivery because of published evidence of teratogenicity in animal studies (19). To improve maternal and fetal outcomes and explore their relationship to clinical signs and symptoms, we retrospectively analyzed $>9$ years of records at a hospital in Nigeria that treated a substantial number of LF cases and applied both a more conservative approach to obstetric management and more liberal antepartum use of ribavirin.

\section{Methods}

Irrua Specialist Teaching Hospital (ISTH) is a tertiary-care federal hospital that served as the LF national referral center for the duration of our study. Providers at ISTH and outside facilities in $>30$ states refer specimens for Lassa virus (LASV) testing by reverse-transcription PCR (RT-PCR) for patients who fit our previously described case definition (20); outside patients who test positive by RT-PCR are often referred to ISTH for management. Two authors (S.O. 
and J.O.) reviewed and abstracted from hospital medical records clinical data for every laboratory-confirmed case of LF in a pregnant woman eventually admitted to ISTH during January 2009-March 2018. During this period, 44 pregnant women were managed for LF. On initial review of these patient records, we found 30 patients for whom documentation of signs and symptoms at admission and during hospitalization were sufficiently complete for inclusion in this study. Comparison data for facility maternal mortality rates over the same period was based on summaries maintained by the ISTH Department of Obstetrics and Gynaecology.

During the study period, pregnant women with confirmed LF received the same supportive care as nonpregnant LF patients, including intravenous fluids (either normal saline or lactated Ringer solution) to improve organ perfusion. All patients had antimicrobial prophylaxis with broad-spectrum antibiotics (ceftriaxone in most cases) and antimalarial drugs (typically oral artemether/lumefantrine; when required, parenteral treatment was quinine before 2014 and artemether after 2014). Fifteen of the 30 pregnant women in our series received blood transfusions for anemia (defined as packed red cell volume $\leq 25 \%$ ), and 2 women required renal dialysis (they were referred for nephrologic evaluation when urine output was $<0.5 \mathrm{~mL} / \mathrm{kg} / \mathrm{h}$, although final decision to dialyze was clinical).

All patients were treated with intravenous ribavirin, except 2 patients who died shortly after arrival. Intravenous ribavirin treatment was started with a $100 \mathrm{mg} / \mathrm{kg}$ loading dose (two thirds dose on admission, one third 8 hours later), then $16 \mathrm{mg} / \mathrm{kg}$ every 6 hours for 4 days, followed by $8 \mathrm{mg} /$ kg every 8 hours for 6 days. All pregnant women had an ultrasound scan on arrival to confirm fetal cardiac activity. After admission, fetal well-being was monitored at least 2 times each week by using either Doppler velocimetry, a nonstress test, or a biophysical profile, as appropriate for gestational age. We used a conservative obstetric management strategy throughout, only inducing labor in cases of fetal compromise and only performing uterine evacuation in women with fetal death. When uterine evacuation was required, we initiated vaginal misoprostol, dosed as appropriate for gestational age and consistent with International Federation of Gynecology and Obstetrics guidelines $(21,22)$, followed by manual vacuum aspiration and curettage when required.

Before 2014, women who cleared viremia on the basis of RT-PCR results were discharged home and had outpatient weekly follow-up, including a nonstress test or biophysical profile. After 2014, in response to a case of late intrauterine fetal death after discharge, women were kept as inpatients for close monitoring until delivery. In all cases, patients had postpartum follow-up at 2 and 6 weeks after delivery. Newborns were not discharged until $\geq 1$ week after delivery, in accordance with hospital protocol for LASV-exposed infants.

For our study, we defined the first trimester as $<14$ weeks from the first day of the last menstrual period (LMP), the second trimester as 14 weeks to $<28$ weeks from LMP, and the third trimester as $\geq 28$ weeks from LMP. We defined stillbirth as delivery after 28 weeks' gestation of a baby without signs of life (i.e., absent cardiac and respiratory activity). Perinatal mortality rate attributable to LF was defined as the proportion of all pregnancies with laboratory-confirmed maternal diagnosis of LF that ended in either intrauterine fetal death after 28 weeks, stillbirth, or neonatal death in the first week of life. Overall maternal mortality rate was defined as the proportion of women who died while pregnant or within 42 days of the end of pregnancy, irrespective of the duration or site of the pregnancy, from causes related to or aggravated by pregnancy or its management, but not from accidental or incidental causes (23). When discussing maternal mortality rates related to LF in the context of this study, we refer to the proportion of women in whom LF was diagnosed during pregnancy and who did not survive that pregnancy.

For statistical analysis, we calculated the mean $\pm \mathrm{SD}$ for quantitative variables, whereas we used prevalence to characterize qualitative variables. We calculated the univariate correlation between clinical features (signs and symptoms) with maternal and fetal death and then ranked these features by the $\mathrm{p}$ value of their association with maternal outcome (either death or survival) by using a $\chi^{2}$ test with Yates correction. Tests of statistical significance (defined as $\mathrm{p} \leq 0.05$ ) were based on a $95 \% \mathrm{CI}$.

\section{Results}

Forty-four cases of LF in pregnancy were managed at ISTH during the study period, out of a total of 5,048 pregnant women admitted to ISTH during that period. The 30 women for whom we were able to recover complete records were 16-39 years of age (mean \pm SD $28.1 \pm 5.1$ years). These 30 women were admitted at gestational ages of 5-39 weeks (mean $21.6 \pm 10.6$ weeks) (Table 1). Parity ranged from $0-6$ (mean $3.0 \pm 1.6)$. One woman had a twin pregnancy.

We divided clinical signs and symptoms into 2 broad patterns. First, 16 women had complications, defined as either coma, convulsions, irrational behavior, extravaginal bleeding, or oliguria. All of these 16 women were also found to have intrauterine fetal death or an abortive process. Maternal death ensued within $24-48$ hours in $10 / 16$ $(58.8 \%)$ of these cases and, in most cases, uterine evacuation was not completed before death. The second clinical pattern was observed in 14 women who had with milder, nonspecific symptoms, including fever, malaise, cough, and sore throat. Thirteen of these 14 women had a live fetus on ultrasound, and only 1 (7.1\%) of the 14 women died. 
Lassa Fever in Pregnancy, Southern Nigeria

Table 1. Demographic characteristics and outcomes observed in a retrospective cohort study of Lassa fever in pregnancy conducted at Irrua Specialist Teaching Hospital, Irrua, Edo State, Nigeria, January 2009-March 2018*

\begin{tabular}{|c|c|c|c|c|c|c|}
\hline $\begin{array}{l}\text { Year of } \\
\text { diagnosis }\end{array}$ & Maternal age, y & $\begin{array}{c}\text { Fetal gestational } \\
\text { age, wks }\end{array}$ & $\begin{array}{c}\text { Maternal } \\
\text { clinical status } \dagger\end{array}$ & Fetal status & Maternal outcome & Perinatal outcome \\
\hline 2009 & 24 & 10 & Severe & Dead & Died & NA \\
\hline 2009 & 35 & 6 & Severe & Dead & Died & NA \\
\hline 2009 & 28 & 12 & Severe & Dead & Survived & NA \\
\hline 2009 & 29 & 7 & Severe & Dead & Survived & NA \\
\hline 2009 & 31 & 22 & Severe & Dead & Died & NA \\
\hline 2010 & 16 & 33 & Mild† & Alive & Survived & Survived \\
\hline 2010 & 26 & 32 & Severe & Dead & Died & NA \\
\hline 2010 & 37 & 11 & Severe & Dead & Died & NA \\
\hline 2010 & 30 & 31 & Severe & Dead & Survived & NA \\
\hline 2011 & 26 & 24 & Severe & Dead & Died & NA \\
\hline 2011 & 26 & 9 & Severe & Dead & Died & NA \\
\hline 2011 & 32 & 36 & Mild & Alive & Survived & Survived \\
\hline 2011 & 27 & 11 & Severe & Dead & Survived & NA \\
\hline 2012 & 39 & 35 & Mild & Alive & Survived & Died $3 \mathrm{~d}$ after birth \\
\hline 2012 & 26 & 33 & Mild & Alive & Survived & Survived \\
\hline 2013 & 25 & 8 & Severe & Dead & Died & NA \\
\hline 2013 & 30 & 31 & Mild & Alive & Survived & Survived \\
\hline 2013 & 31 & 29 & Mild & Alive & Died & Died at 38 wks \\
\hline 2013 & 32 & 10 & Severe & Dead & Survived & NA \\
\hline 2014 & 18 & 33 & Mild & Dead & Survived & NA \\
\hline 2014 & 28 & 12 & Severe & Dead & Survived & NA \\
\hline 2015 & 26 & 28 & Mild & Alive & Survived & Survived \\
\hline 2016 & 33 & 27 & Mild & Alive & Survived & Survived \\
\hline 2017 & 35 & 34 & Mild & Alive & Survived & Survived \\
\hline 2017 & 32 & 29 & Mild & Alive & Survived & $\begin{array}{c}\text { Twins; } 1 \text { died at } 37 \text { wks, } \\
1 \text { survived }\end{array}$ \\
\hline 2017 & 23 & 32 & Severe & Dead & Died & NA \\
\hline 2017 & 24 & 31 & Mild & Alive & Survived & Survived \\
\hline 2017 & 36 & 25 & Severe & Dead & Died & NA \\
\hline 2018 & 33 & 29 & Mild & Alive & Survived & Survived \\
\hline 2018 & 32 & 33 & Severe & Alive & Survived & Survived \\
\hline
\end{tabular}

Irrespective of initial signs and symptoms, in all cases of intrauterine fetal death, uterine evacuation was initiated using misoprostol vaginal tablets as we described. Four of these patients died before complete evacuation, and 5 women required manual vacuum aspiration for evacuation of retained products of conception.

All 30 women had fever. Overall, 19 women survived and 11 died, resulting in an overall LF-related maternal mortality rate of $36.7 \%$ in this cohort. Seven of the 11 deaths occurred within 24 hours of admission, and 4 occurred within 24-48 hours of admission. Fetal death in utero, retrosternal chest pain, vomiting, and cough were the most frequent clinical features apart from fever, whereas deafness was the least frequent (Table 2). Extravaginal bleeding, convulsions, oliguria, fetal death in utero, and cough were each significantly associated with maternal death. In contrast, admission with a live fetus and breast pain or engorgement were each significantly associated with survival.

The mean \pm SD duration of symptoms before admission was $6 \pm 3.1$ days among the survivors and $10 \pm 3.5$ days among those who died. When divided by trimester of pregnancy, maternal mortality rate was $50.0 \%(5 / 10)$ in the first, $75.0 \%(3 / 4)$ in the second, and $18.7 \%(3 / 16)$ in the third trimester. We noted a trend toward a lower maternal mortality rate in the third trimester, but this difference did not reach statistical significance $(\mathrm{p}=0.06)$. Overall, deaths attributed to LF accounted for $13.1 \%$ (11/84, out of 5,048 total admissions of pregnant women) of maternal deaths at ISTH during the study period, second only to postpartum hemorrhage (28.5\%) and eclampsia (22.6\%).

Overall, 17/31 (56.7\%) of fetuses had died by the time of admission. Of the 13 women with viable pregnancies at admission, 1 had a twin gestation and subsequently delivered 1 live baby (Apgar score 4 at 1 minute, 8 by 5 minutes) without apparent abnormality and 1 stillbirth at term. Another patient returned with delayed intrauterine fetal death at 38 weeks' gestation, despite having cleared her viremia after initial examination 9 weeks earlier, and died shortly after the return admission; a repeat LASV RT-PCR test was not performed. Five of the women with viable pregnancies at discharge had full-term deliveries, 5 had preterm deliveries at 33-36 weeks' gestation, and 1 had early neonatal death on the third day of life. The rate of perinatal death or spontaneous abortion in women who were admitted with a live fetus was $21.4 \%$ (3/14), compared with an overall rate of fetal and perinatal loss of $64.5 \%(20 / 31)$. 
Table 2. Relationship between clinical manifestations and maternal death observed in a retrospective cohort study of Lassa fever in pregnancy conducted at Irrua Specialist Teaching Hospital, Irrua, Edo State, Nigeria, January 2009-March 2018*

\begin{tabular}{|c|c|c|c|c|c|}
\hline \multirow[b]{2}{*}{ Sign or symptom } & \multicolumn{3}{|c|}{ No. (\%) } & \multirow[b]{2}{*}{$p$ value } & \multirow[b]{2}{*}{ OR $(95 \% \mathrm{Cl})$} \\
\hline & All women, $\mathrm{N}=30$ & $\begin{array}{l}\text { Women who survived, } \\
\mathrm{n}=19\end{array}$ & $\begin{array}{l}\text { Women who died, } \\
n=11\end{array}$ & & \\
\hline Retrosternal pain & $19(63)$ & $13(68)$ & $6(54)$ & 0.7 & $0.55(0.12-2.6)$ \\
\hline Vomiting & $18(60)$ & $12(63)$ & $6(54)$ & 0.7 & $0.7(0.15-3.2)$ \\
\hline Headache & $16(53)$ & $13(68)$ & $3(27)$ & 0.06 & $0.17(0.03-0.89)$ \\
\hline Fetal death & $17(56)$ & $7(36)$ & $10(90)$ & 0.007 & $17(1.8->100)$ \\
\hline Vaginal bleeding & $14(46)$ & $6(31)$ & $8(72)$ & 0.06 & $5.8(1.1-30)$ \\
\hline Breast pain or engorgement & $13(43)$ & $12(63)$ & $1(9)$ & 0.007 & $0.06(0.01-0.56)$ \\
\hline Difficulty swallowing & $12(40)$ & $6(31)$ & $6(54)$ & 0.3 & $2.6(0.56-12)$ \\
\hline Sore throat & $11(36)$ & $6(31)$ & $5(45)$ & 0.7 & $1.8(0.39-8.3)$ \\
\hline Abdominal pain & $10(33)$ & $6(31)$ & $4(36)$ & 1 & $1.2(0.26-5.9)$ \\
\hline Cough & $10(33)$ & $3(15)$ & $7(63)$ & 0.01 & $9.3(1.6-53)$ \\
\hline Extravaginal bleeding & $9(30)$ & $0(0)$ & $9(81)$ & $<0.0001$ & $>100(0->100)$ \\
\hline Renal angle tenderness & $9(30)$ & $6(31)$ & $3(27)$ & 1 & $0.81(0.16-4.2)$ \\
\hline Convulsions & $8(26)$ & $1(5)$ & $7(63)$ & 0.001 & $31(3->100)$ \\
\hline Oliguria† & $8(26)$ & $1(5)$ & $7(63)$ & 0.001 & $32(3->100)$ \\
\hline Preterm contractions & $8(26)$ & $7(36)$ & $1(9)$ & 0.2 & $0.17(0.02-1.6)$ \\
\hline Jaundice & $7(23)$ & $2(10)$ & $5(45)$ & 0.07 & $7.1(1.1-47)$ \\
\hline Deafness & $5(16)$ & $3(15)$ & $2(18)$ & 1 & $1.2(0.17-8.5)$ \\
\hline
\end{tabular}

In relation to the fetus, the mortality rate was significantly lower when the mother was admitted to the hospital in the third trimester; the rate was $31.2 \%(6 / 17)$ for the third trimester compared with $92.9 \%(13 / 14)$ for the first and second trimesters combined $(\mathrm{p}<0.001)$. Maternal signs and symptoms that included extravaginal bleeding, convulsions, oliguria, or vaginal bleeding were each associated with fetal death $(\mathrm{p}<0.01)$ (Table 2$)$.

Finally, we noted that $17(56.7 \%)$ of the 30 women had been to other health facilities before admission, whereas the remaining 13 (43.3\%) patients sought care at our hospital as their first point of call. Among the 17 women from other facilities, LF was suspected in 8 cases; differential diagnoses included eclampsia, malaria, pyelonephritis, miscarriage, puerperal sepsis, and placenta previa.

\section{Discussion}

LF is endemic to several states in Nigeria, and the number of women at risk for LASV infection during pregnancy is high. Our study highlights the contribution of LF to maternal mortality rates at a teaching hospital in Nigeria, where LF was diagnosed in $44 / 5,048(0.87 \%)$ of all admitted pregnant women but accounted for 11/84 (13.1\%) of maternal deaths at the facility during the study period. The $36.7 \%$ LF-related maternal mortality rate we report is roughly in the range of a case series described in Sierra Leone in 1988 (21\%) (11) and of limited data from Liberia (where the LFrelated mortality rate reported before 1973 was 33\%-75\%) (24), although detailed comparison is difficult given the sample sizes involved, decades of separation, and different geographic and genetic contexts.

Most of the deaths in our case series occurred during 2009-2013 (9/19, 47.4\%); the mortality rate decreased by more than half for 2014-2018 (2/11, 18.2\%). Despite the relatively small numbers in our study, a few key changes occurred in Nigeria, and specifically at ISTH, that are consistent with dropping mortality rates. First, testing of LF and other viral hemorrhagic fevers increased after the 2013-2016 Ebola virus disease outbreak. Second, ISTH has dramatically increased resources devoted to LF research and clinical care. Third, public health activities at ISTH and throughout Edo State increased, including a series of community campaigns and seminars for healthcare workers, with the goal of raising awareness of LF and improving management strategies.

Ongoing public health efforts presume the importance of timely referrals and quick diagnosis of LF, given that poor health-seeking behaviors resulting from lack of awareness are believed to delay medical care and worsen outcomes $(17,25)$. Furthermore, in our study, $64 \%$ of maternal deaths occurred within 24 hours of admission and $100 \%$ within 48 hours of admission, suggesting that the disease was often advanced before referrals were made, a finding consistent with previously described delays in care for other obstetric complications (26). This observation further emphasizes the need for continuous community engagement, healthcare worker sensitization, an increased index of suspicion in LF-endemic areas, and ready availability of rapid diagnostic tools. The actual contribution of LF to maternal mortality rates is likely underreported in Nigeria, and we suspect LF constitutes a hidden cause of maternal deaths in several LF-endemic communities in a country that already has one of the highest maternal mortality rates in the world $(27,28)$.

Extravaginal bleeding, convulsions, and oliguria have been found to be associated with poor outcomes in 
nonpregnant adults (16), and we have found similar associations in maternal and fetal prognosis. In addition, we report the concerning finding that more than half of mothers who were admitted to our hospital with a deceased fetus eventually died themselves. This finding is consistent with the experience reported from Sierra Leone in 1988 (11), although the causal relationship between intrauterine death and severe LF disease is unknown. The number of cases in our retrospective series was insufficient to compare strategies of evacuation alone, evacuation and ribavirin, or ribavirin alone; further studies are needed to determine the best approach to obstetric care.

Although in Sierra Leone a major correlate of poor outcome was the diagnosis of LF in the third trimester (11), we did not observe the same correlation. Many factors might have contributed to this difference; however, we note that the Sierra Leone study endorsed active uterine evacuation in the third trimester and deferred ribavirin (11), whereas ISTH uses ribavirin as early therapy in all cases. Because ribavirin has been reported to be teratogenic in animal studies and data on its safety in pregnant women are insufficient (19), our decision to use this treatment was not taken lightly. However, although high-quality efficacy trials are lacking and safety data are pending, ribavirin is one of few therapeutic modalities available to us in this situation. The results in terms of maternal and fetal outcomes have been positive in our experience.

The favorable maternal outcome associated with admission with a live fetus suggests the importance of early detection, and we believe the results acquired through our conservative management of these patients challenge the view that active uterine evacuation is required, at least in our setting. Although we did find a significant risk of fetal death overall, we are encouraged because 12 of the 13 women admitted with live fetuses survived the illness, and 11 live births resulted. Our single experience with late uterine death of unexplained cause did increase our surveillance of pregnant survivors of LF, and we now admit such women for more frequent fetal monitoring (biometric and biophysical surveillance) and the option to induce labor in case of fetal compromise.

The generalizability of our findings is limited by a relatively small sample size at a single tertiary-care hospital and the exclusion of several cases because of incomplete records. We further recognize that we lack clinical laboratory data, quantitative RT-PCR assays needed to assess viral load, and pathologic confirmation of cause of death. Although availability of these data points has improved over time at our hospital, we note that they are not always routinely available in our resource-limited setting. We have instead highlighted key clinical findings associated with poor prognosis, including extravaginal bleeding, convulsions, oliguria, and fetal death, that do not require infrastructure for laboratory or pathologic confirmation. In our hospital, women with any of these signs or symptoms receive emergent and aggressive supportive care, including ribavirin therapy.

In conclusion, LF in pregnancy has a high case-fatality rate and is an important and likely underreported cause of maternal death in LF-endemic areas of Nigeria and in other West African countries. Admission to care with a live fetus is predictive of improved maternal outcome, and conservative obstetric management with early ribavirin (instead of evacuation) is producing good outcomes in our hands. Further studies are needed to confirm these conclusions and to provide an updated, data-driven algorithm for clinical management of pregnant women with LF.

\section{About the Author}

Dr. Okogbenin is a professor of fetal-maternal medicine and infectious diseases expert at Ambrose Alli University Ekpoma as well as a consultant obstetrician and gynecologist at ISTH. He is the chief medical director of ISTH.

\section{References}

1. Knobloch J, McCormick JB, Webb PA, Dietrich M, Schumacher HH, Dennis E. Clinical observations in 42 patients with Lassa fever. Tropenmed Parasitol. 1980;31:389-98.

2. Richmond JK, Baglole DJ. Lassa fever: epidemiology, clinical features, and social consequences. BMJ. 2003;327:1271-5. http://dx.doi.org/10.1136/bmj.327.7426.1271

3. Houlihan C, Behrens R. Lassa fever. BMJ. 2017;358:j2986. http://dx.doi.org/10.1136/bmj.j2986

4. Frame JD, Baldwin JM Jr, Gocke DJ, Troup JM. Lassa fever, a new virus disease of man from West Africa. I. Clinical description and pathological findings. Am J Trop Med Hyg. 1970;19:670-6. http://dx.doi.org/10.4269/ajtmh.1970.19.670

5. Buckley SM, Casals J. Lassa fever, a new virus disease of man from West Africa. 3. Isolation and characterization of the virus. Am J Trop Med Hyg. 1970;19:680-91. http://dx.doi.org/10.4269/ ajtmh.1970.19.680

6. Jahrling PB, Frame JD, Smith SB, Monson MH. Endemic Lassa fever in Liberia. III. Characterization of Lassa virus isolates. Trans R Soc Trop Med Hyg. 1985;79:374-9. http://dx.doi.org/ 10.1016/0035-9203(85)90386-4

7. Fraser DW, Campbell CC, Monath TP, Goff PA, Gregg MB. Lassa fever in the Eastern Province of Sierra Leone, 1970-1972. I. Epidemiologic studies. Am J Trop Med Hyg. 1974;23:1131-9. http://dx.doi.org/10.4269/ajtmh.1974.23.1131

8. Frame JD. Surveillance of Lassa fever in missionaries stationed in West Africa. Bull World Health Organ. 1975;52:593-8.

9. Ogbu O, Ajuluchukwu E, Uneke CJ. Lassa fever in West African sub-region: an overview. J Vector Borne Dis. 2007;44:1-11.

10. Keane E, Gilles HM. Lassa fever in Panguma Hospital, Sierra Leone, 1973-6. BMJ. 1977;1:1399-402. http://dx.doi.org/10.1136/ bmj.1.6073.1399

11. Price ME, Fisher-Hoch SP, Craven RB, McCormick JB. A prospective study of maternal and fetal outcome in acute Lassa fever infection during pregnancy. BMJ. 1988;297:584-7. http://dx.doi.org/10.1136/bmj.297.6648.584

12. Andersen KG, Shapiro BJ, Matranga CB, Sealfon R, Lin AE, Moses LM, et al.; Viral Hemorrhagic Fever Consortium. Clinical sequencing uncovers origins and evolution of Lassa virus. Cell. 2015;162:738-50. http://dx.doi.org/10.1016/j.cell.2015.07.020 
13. McCormick JB, King IJ, Webb PA, Johnson KM, O'Sullivan R, Smith ES, et al. A case-control study of the clinical diagnosis and course of Lassa fever. J Infect Dis. 1987;155:445-55. http://dx.doi.org/10.1093/infdis/155.3.445

14. Walker DH, McCormick JB, Johnson KM, Webb PA, Komba-Kono G, Elliott LH, et al. Pathologic and virologic study of fatal Lassa fever in man. Am J Pathol. 1982;107:349-56.

15. Mor G, Cardenas I. The immune system in pregnancy: a unique complexity. Am J Reprod Immunol. 2010;63:425-33. http://dx.doi.org/10.1111/j.1600-0897.2010.00836.x

16. Okokhere P, Colubri A, Azubike C, Iruolagbe C, Osazuwa O, Tabrizi S, et al. Clinical and laboratory predictors of Lassa fever outcome in a dedicated treatment facility in Nigeria: a retrospective, observational cohort study. Lancet Infect Dis. 2018;18:684-95. http://dx.doi.org/10.1016/S1473-3099(18)30121-X

17. McCormick JB, King IJ, Webb PA, Scribner CL, Craven RB, Johnson KM, et al. Lassa fever. Effective therapy with ribavirin. N Engl J Med. 1986;314:20-6. http://dx.doi.org/10.1056/ NEJM198601023140104

18. Bausch DG, Hadi CM, Khan SH, Lertora JJL. Review of the literature and proposed guidelines for the use of oral ribavirin as postexposure prophylaxis for Lassa fever. Clin Infect Dis. 2010;51:1435-41. http://dx.doi.org/10.1086/657315

19. Sinclair SM, Jones JK, Miller RK, Greene MF, Kwo PY, Maddrey WC. The Ribavirin Pregnancy Registry: an interim analysis of potential teratogenicity at the mid-point of enrollment. Drug Saf. 2017;40:1205-18. http://dx.doi.org/10.1007/s40264-017-0566-6

20. Asogun DA, Adomeh DI, Ehimuan J, Odia I, Hass M, Gabriel $\mathrm{M}$, et al. Molecular diagnostics for Lassa fever at Irrua Specialist Teaching Hospital, Nigeria: lessons learnt from two years of laboratory operation. PLoS Negl Trop Dis. 2012;6:e1839. http://dx.doi.org/10.1371/journal.pntd.0001839

21. Gómez Ponce de León R, Wing D, Fiala C. Misoprostol for intrauterine fetal death. Int J Gynaecol Obstet. 2007;99(Suppl 2):S190-3. http://dx.doi.org/10.1016/j.ijgo.2007.09.010

22. International Federation of Gynecology and Obstetrics. Prevention of post-partum haemorrhage with misoprostol [cited 2019 Feb 21] https://www.figo.org/sites/default/files/uploads/project-publications/ Miso/PPH\%20prevention/Prevention\%20of\%20PPH\%20with\%20 Misoprostol_In\%20Brief_2012_English.pdf

23. World Health Organization. The WHO application of ICD-10 to deaths during pregnancy, childbirth and puerperium: ICD MM [cited 2019 Feb 21]. https://apps.who.int/iris/bitstream/ handle/10665/70929/9789241548458_eng.pdf

24. Monath TP, Mertens PE, Patton R, Moser CR, Baum JJ, Pinneo L, et al. A hospital epidemic of Lassa fever in Zorzor, Liberia, March-April 1972. Am J Trop Med Hyg. 1973;22:773-9. http://dx.doi.org/10.4269/ajtmh.1973.22.773

25. Faith I, O AA, Samuel MK, Ifeanyi O, Ekundare FO, Danny A, et al. An assessment of onset-to-intervention time and outcome of Lassa fever during an outbreak in Edo State, Nigeria. International Journal of Prevention and Treatment. 2018;7:1-5.

26. Adamu YM, Salihu HM, Sathiakumar N, Alexander GR. Maternal mortality in Northern Nigeria: a population-based study. Eur J Obstet Gynecol Reprod Biol. 2003;109:153-9. http://dx.doi.org/ 10.1016/S0301-2115(03)00009-5

27. Okonofua FE, Abejide A, Makanjuola RA. Maternal mortality in Ile-Ife, Nigeria: a study of risk factors. Stud Fam Plann. 1992; 23:319-24. http://dx.doi.org/10.2307/1966529

28. Harrison KA. Maternal mortality in Nigeria: the real issues. Afr J Reprod Health. 1997;1:7-13. http://dx.doi.org/10.2307/3583270

Address for correspondence: Sylvanus Okogbenin, Irrua Specialist Teaching Hospital, KM 87, Benin Auchi Rd, PMB 08, Irrua, Edo State, Nigeria; email: okogbenins@yahoo.com

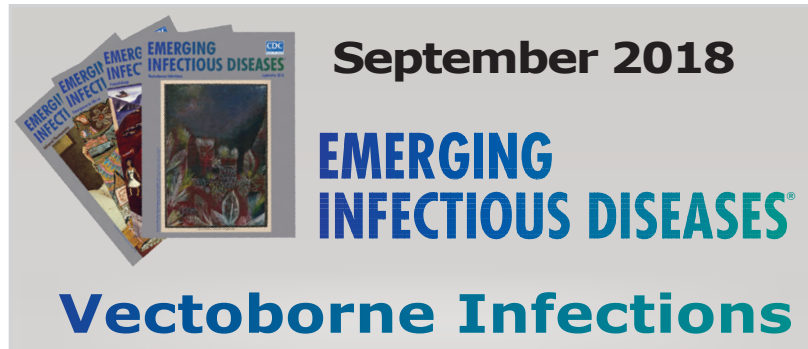

- Ethics of Infection Control Measures for Carriers of Antimicrobial Drug-Resistant Organisms

- National Surveillance for Clostridioides difficile Infection, Sweden, 2009-2016

- Travel-Associated Zika Cases and Threat of Local Transmission during Global Outbreak, California, USA

- Distinguishing Japanese Spotted Fever and Scrub Typhus, Central Japan, 2004-2015

- Event-Based Surveillance at Community and Healthcare Facilities, Vietnam, 2016-2017

- Case Report and Genetic Sequence Analysis of Candidatus Borrelia kalaharica, Southern Africa

- Novel Orthopoxvirus and Lethal Disease in Cat, Italy

- Emergence of Carbapenemase-Producing Enterobacteriaceae, South-Central Ontario, Canada

- From Culturomics to Clinical Microbiology and Forward

- Association of Batai Virus Infection and Encephalitis in Harbor Seals, Germany, 2016

- Use of Favipiravir to Treat Lassa Virus Infection in Macaques

- Aortic Endograft Infection with Mycobacterium chimaera and Granulicatella adiacens, Switzerland, 2014

- Estimating Frequency of Probable Autochthonous Cases of Dengue, Japan

- Correlation of Severity of Human Tick-borne Encephalitis Virus Disease and Pathogenicity in Mice

- Increasing Prevalence of Borrelia burgdorferi sensu strictoInfected Blacklegged Ticks in Tennessee Valley, Tennessee, USA

- Susceptibility of White-Tailed Deer to Rift Valley Fever Virus

- Outbreak of Pneumococcal Meningitis, Paoua Subprefecture, Central African Republic, 2016-2017

- Molecular Confirmation of Rocky Mountain Spotted Fever Epidemic Agent in Mexicali, Mexico

- Fatal Tickborne Phlebovirus Infection in Captive Cheetahs, Japan

- Zika Virus Seropositivity in 1-4-Year-Old Children, Indonesia, 2014

\section{To revisit the September 2018 issue, go to: https://wwwnc.cdc.gov/eid/articles/ issue/24/9/table-of-contents}

